\title{
THE DIFFERENCES OF DEPRESSIVE SYMPTOMS BY GENDER IN PEOPLE WITH PSORIASIS
}

\author{
ANNISA FRANSISKA*, SURYA HUSADA M, ELMEIDA EFFENDY
}

Department of Psychiatry, Faculty of Medical, Universitas Sumatera Utara, USU-Kampus, Medan 20155, Indonesia. Email: ikoy2208@gmail.com

Received: 16 October 2017, Revised and Accepted: 22 October 2017

ABSTRACT

Objectives: The objectives of the study were to determine the differences of depressive symptoms by gender in people with psoriasis.

Methods: This study was a comparative analytical study with cross-sectional approach, the sampling techniques using non-probability sampling with consecutive sampling techniques types. Place of study: Psoriasis foundation Medan research time: January 2014-March 2014. Every patient who meets the criteria of psoriasis vulgaris patients aged 16-60 years, disease duration $>6$ months, able to read and write, cooperative and willing to participate in the study, did not suffer severe medical illness, did not suffer from other mental disorders, and not using illicit substances included in the study, and then, to assess depressive symptoms using a questionnaire beck depression inventory-II.

Results: A total of 80 patients were evenly split into groups of men and women have the highest life characteristics at $16-38$ years (55\% and 72.5\%). Highest education in higher education both $95 \%$ and the severity of depressive symptoms was also a lot of artifacts on minimal depressive symptoms $(82.5 \%$ and $72.5 \%)$. Cross-table test showed no significant difference in depressive symptoms between men and women ( $\mathrm{p}>0.05)$.

Conclusion: Overall in people with psoriasis there was no significant difference of depressive symptoms by gender for the entire data.

Keywords: Beck depression inventory-II, Psoriasis, Depressive symptoms.

(C) 2018 The Authors. Published by Innovare Academic Sciences Pvt Ltd. This is an open access article under the CC BY license (http://creativecommons. org/licenses/by/4. 0/) DOI: http://dx.doi.org/10.22159/ajpcr.2018.v11s1.26564

\section{INTRODUCTION}

Psoriasis is a chronic skin disorder that affects $1-3 \%$ of the population in the world and an estimated $0.4-2.3 \%$ of the adult population suffers from psoriasis but not diagnosed [1]. According to the Foundation Psoriasis sufferers in Indonesia journals, the estimated number of people with psoriasis in Indonesia could reach 2 to 6 million people, but the overall accumulation of Psoriasis Indonesia Foundation and the Indonesian Ministry of Health (MOH RI) of the estimated 2\%, or about 2 million people with psoriasis in Indonesia only 3000 people with psoriasis are approximately $0.075 \%$ recorded in the year 2010 [2].

In young people psoriasis most commonly found at the age of 16 and 22 years while in the elderly at the age of 57 and 60 years. The incidences of psoriasis between men and women were equal. However, women are more likely to the disease earlier than men $[3,4]$.

Patients with psoriasis frequently appear with a physical disability, social discomfort, and psychological disorders. Shyness and social anxiety often the caused by the disease causes relational conflicts, creating an emotional distance, self-isolation, and depression that affect the quality of life of people with psoriasis with stress relatedpsoriasis [5]. More pertinent with psychosocial difficulties inherent in interpersonal relationships of people with psoriasis compared with the severity or chronicity of psoriasis disease activity itself [6]

Clinically, the severity of psoriasis is described by the intensity and extent of psoriasis lesions. From the standpoint of patients, the impact psoriasis has affected the daily reviews their physical, social, and most importantly, psoriasis has affected reviews their psychological and emotional functioning. A subgroup of patients with psoriasis symptoms in an objective light but considers having severe disease severity subjectively [7].

Patients with psoriasis have been reported to have a high prevalence of depressive disorders mayor [8]. Approximately 79\% of patients feel the disturbed quality of life, $31-57 \%$ experienced stress, and $25 \%$ have depression [9]. According to previous studies, the prevalence of depression in patients with psoriasis ranged 0-58\% [2,3].

Based on Golpour et al. study, in 2007, in Iran than a 100 patients in each group $44(45 \%)$ were men and $56(55 \%)$ were women in getting the prevalence of people with psoriasis who experience depression is $67 \%$ and in control of $12 \%$ where the proportion of women with psoriasis who are depressed are $21.4 \%$ and the proportion of men patients with psoriasis who are depressed is $23.9 \%$ [4]

Having regard to the background problems, this study formulated the problems: Are there differences in depressive symptoms by gender in people with psoriasis? The benefit of this study was expected to provide information about depressive symptoms in people with psoriasis based on gender to provide feedback, early detected, and anticipated where there necessary further treatment.

Psoriasis is an autoimmune disease that is chronic, an inflammatory and proliferative condition of the skin, where genetic and environmental influences play an important role. Psoriasis is characterized by a distinctive lesion of tightly defined erythema, covered by a thick, glossy, transparent white-coated skuama with the phenomenon of wax droplets [10-12].

The diagnosis of psoriasis is made based on the presence of distinctive skin lesions. There is no specific blood test or diagnostic procedure. If necessary, a skin biopsy or scraping is required to rule out other diagnoses and to confirm the diagnosis, but this is rarely done [13].

Depression is defined as a mental state characterized by feelings of sadness, loneliness, despair, low self-esteem, and self-humiliation, accompanying signs including psychomotor retardation, agitation, withdrawal from interpersonal relations, and characterized by the presence of vegetative symptoms, such as insomnia and anorexia. This term refers to a depressed mood or mood disorder [14]. 
This description tends to describe painful emotions, usually perceived as severe physical pain. Thus, the feeling of depression has a somatic quality that is painfully painful. Suicide may be an attempt to find relief from unrelenting psychic torture [15].

Treatment of psoriasis is usually difficult and often unsatisfactory. The emotional suffering caused by psoriasis can lead to depression and suicidal ideation. Recent studies have shown that psoriasis is associated with high risk of suicide [16].

Study on the relationship between psoriasis and mental health disorders states that patients with psoriasis have a $39 \%$ increased risk of depression, 31\% increased risk of anxiety, and 44\% increased risk of suicide. The prevalence of depression in patients with moderate-tosevere psoriasis is about $24 \%$, as many as $60 \%$ of psoriasis patients report clinical psychiatric symptoms [17].

The Beck Depression Inventory-II (BDI-II) is widely used as an indicator of the severity of depression, but not as a diagnostic tool and many studies provide evidence for reliability and validity across populations and cultural groups. The items on BDI-II were developed to assess depression symptoms based on the criteria found in Diagnostic and statistical manual of mental disorder, $4^{\text {th }}$ edition (DSM-IV) for depressive disorders. Scores from 0 to 13 show minimal depression, 1419 indicating mild depression, 20-28 indicating moderate depression, and 29-63 indicating severe depression [18].

This instrument was also used as a screening, can be used to assess depression in clinical and non-clinical environments [19,20].

\section{METHODS}

This study is a comparative analytic using cross-sectional design and was conducted in Medan Psoriasis Foundation. This study was carried out within a period of 2 months from January to March 2014. The population target was people with psoriasis.

People with vulgaris psoriasis, who have met psoriasis clinical diagnosis by a specialist in skin and venereal diseases with disease duration more than 6 months, age between 16 and 60-year-old, able to read and write, cooperative, and willing to participate would be included in this study. Suffering from severe medical illness, other mental disorders, or and using a banned substance would be excluded. The obtained sample number is rounded to 80 people consisting of 40 men and 40 women. Sampling was done by purposive sampling. All the study subjects were asked for its approval by first briefed before be included as a research subject. The approved number was 116/KOMET/FK USU/2014.

Management of study was people with psoriasis who have been diagnosed by a specialist in skin and venereal diseases and is listed as a member of Psoriasis Foundation Medan who meets the inclusion and exclusion criteria were required to provide written consent after being given a detailed explanation. Furthermore, all subjects were asked to filled identity and demographic characteristics data; then all subjects were asked to fill out a BDI-II questionnaire. The data would be collected and the processing of data presented in tabular form. In addition, there was the identification of each of depressive symptoms by gender in people with psoriasis.

\section{RESULTS}

There were 40 subjects each in men and women group (Table 1) from the table contains characteristics of age, the age category 16-38 years was more common, whereas 22 subjects (55\%) in men and $29(72.5 \%)$ in women. Higher education category was more prevalent in both groups, and married category is more prevalent both on a group of men and women, there were 31 subjects $(77,5 \%)$ in men and 30 subjects $(75 \%)$ in women. Work category was more prevalent both on a group of men and women, where a total of men 39 subjects (97.5\%) and in women by
23 subjects (77.5\%). From the severity characteristics of depression, normal was more common both in the group of men and women, for men were 33 subjects (82.5\%) and women were 29 subjects $(72.5 \%)$.

Compared of depressive symptoms (Table 2) there was no significant difference between BDI scores and people with psoriasis by gender. There were several differences scores on some depressive symptoms between men and women: the symptom of loss of pleasure (BDI-IV), 20 men (50\%) choosed score of 1 (I enjoyed less than I ever used to) and 23 women (57\%) choosed score of 0 (I get as much pleasure as I ever did from all the things that I enjoy).

The differences in symptoms of agitation (BDI-XI) 22 men (55\%) choosed score of 1 (I feel less able to rest as usual) and 19 women $(47,5 \%)$ choosed on score of 0 (I can rested as usual) and the symptoms of changes in appetite (BDI-XVIII), men was widely available on a score of 0 (I didn't get any changes in my appetite) for 25 subjects $(62.5 \%)$ and women on a score of 1 (my appetite sometimes more than usual or less than usual) for 20 subjects (50\%).

\section{DISCUSSION}

This study was an analytic study with cross-sectional approach category to see the differences depressive symptoms by gender in people with psoriasis in Medan Psoriasis Foundation. According to the best of our knowledge, this is the first study in assessing depressive symptoms by gender in people with psoriasis in Medan.

We noted that there were no significant differences in each of the symptoms of depressive between men and women on a scale of BDI-II, but the proportion in some symptoms such as symptoms of loss of pleasure (BDI-IV), the differences in symptoms of agitation (BDI-XI), and the symptoms changes in appetite (BDI-XVIII); but there were no significant differences in the overall the data $(p>0.05)$.

The lacking of this study is that the study did not distinguish between the severity of psoriasis and the size and location of the lesion. This study is the first to examine the differences in depressive symptoms in people with psoriasis by gender so that it can be used as a reference for a larger study.

\section{CONCLUSION}

There were no difference depressive symptoms by gender in people with psoriasis.

The depressive severity of the men and women group in most people with psoriasis is at the minimum/normal depressive severity. In

Table 1: Demographic characteristics

\begin{tabular}{|c|c|c|}
\hline \multirow[t]{2}{*}{ Characteristics } & \multicolumn{2}{|l|}{ Gender } \\
\hline & Men $n=40(\%)$ & Women $n=40(\%)$ \\
\hline \multicolumn{3}{|l|}{ Age (years) } \\
\hline $16-38$ & $22(55)$ & $29(72.5)$ \\
\hline $39-60$ & $18(45)$ & $11(27.5)$ \\
\hline \multicolumn{3}{|l|}{ Education } \\
\hline Low & $2(5)$ & $2(5)$ \\
\hline High & $38(95)$ & $38(95)$ \\
\hline \multicolumn{3}{|l|}{ Marital status } \\
\hline Married & $31(77.5)$ & $30(75)$ \\
\hline Not married & $9(22.5)$ & $10(25)$ \\
\hline \multicolumn{3}{|l|}{ Work } \\
\hline Work & $39(97.5)$ & $23(77.5)$ \\
\hline Does not work & $1(2.5)$ & $17(22.5)$ \\
\hline \multicolumn{3}{|l|}{ Level of depression } \\
\hline Normal & $33(82.5)$ & $29(72.5)$ \\
\hline Mild depression & $5(12.5)$ & $8(20)$ \\
\hline Moderate depression & $1(2.5)$ & $2(5)$ \\
\hline Major depression & $1(2.5)$ & $1(2.5)$ \\
\hline
\end{tabular}


Table 2: Depressive symptom on BDI-II scale by gender

\begin{tabular}{|c|c|c|c|}
\hline \multirow[t]{2}{*}{ Characteristics } & \multicolumn{2}{|l|}{ Gender } & \multirow[t]{2}{*}{$\mathbf{p}$} \\
\hline & Men $n=40(\%)$ & Women $n=40(\%)$ & \\
\hline \multicolumn{4}{|l|}{ BDI-01 (sadness) } \\
\hline $0=I$ do not feel sad & $28(70)$ & $24(60)$ & \\
\hline $1=$ I feel sad so often & $11(27.5)$ & $16(40)$ & $0.429 *$ \\
\hline $2=\mathrm{I}$ feel sad all of the time & $1(2.5)$ & $0(0)$ & \\
\hline \multicolumn{4}{|l|}{ BDI-02 (pessimism) } \\
\hline $0=\mathrm{I}$ do not afraid of my future & $32(80)$ & $34(85)$ & \\
\hline $1=\mathrm{I}$ am afraid of my future more than I used to & $7(17.5)$ & $6(15)$ & $1.000^{*}$ \\
\hline $\begin{array}{l}2=I \text { am so hopeless with my future, and I believe that the situation is only } \\
\text { getting worse }\end{array}$ & $1(2.5)$ & $0(0)$ & \\
\hline \multicolumn{4}{|l|}{ BDI-03 (past failure) } \\
\hline $0=\mathrm{I}$ do not feel like a failure & $25(62.5)$ & $27(67.5)$ & \\
\hline $1=\mathrm{I}$ have failed more than I should have & $7(17.5)$ & $8(20)$ & $0.476^{*}$ \\
\hline 2=As I look back. I see so many failure & $8(20)$ & $5(12.5)$ & \\
\hline \multicolumn{4}{|l|}{ BDI-04 (loss of pleasure) } \\
\hline $2=I$ have so little pleasure from all the things that usually I enjoyed myself & $5(12.5)$ & $2(5)$ & \\
\hline $\begin{array}{l}3=\text { I do not have any pleasure from all the things that usually I enjoyed } \\
\text { myself }\end{array}$ & $1(2.5)$ & $0(0)$ & \\
\hline \multicolumn{4}{|l|}{ BDI-05 (guilty feelings) } \\
\hline $0=\mathrm{I}$ do not feel any guilty & $20(50)$ & $22(55)$ & \\
\hline $1=$ I feel guilty for most of the things that I have done or should have done & $17(42.5)$ & $17(42.5)$ & $0.606^{*}$ \\
\hline $2=I$ feel guilty for all the time & $3(7.5)$ & $1(2.5)$ & \\
\hline \multicolumn{4}{|l|}{ BDI-06 (punishment feelings) } \\
\hline $0=I$ don't feel I am being punished & $28(70)$ & $28(70)$ & \\
\hline $1=$ I feel I might be punished & $9(22.5)$ & $9(22.5)$ & $1.000^{*}$ \\
\hline $2=I$ expect to be punished & $1(2.5)$ & $0(0)$ & \\
\hline $3=\mathrm{I}$ feel I am being punished & $2(5)$ & $3(7.5)$ & \\
\hline \multicolumn{4}{|l|}{ BDI-07 (self-loathing) } \\
\hline $0=I$ feel the same as I ever be & $31(77.5)$ & $30(75)$ & \\
\hline $1=\mathrm{I}$ have lost a faith in myself & $7(17.5)$ & $8(20)$ & $1.000^{*}$ \\
\hline $2=\mathrm{I}$ disappointed with myself & $2(5)$ & $2(5)$ & \\
\hline $2=I^{\prime} m$ criticized of myself for all my faults & $8(20)$ & $8(20)$ & \\
\hline \multicolumn{4}{|l|}{ BDI-09 (suicidal thoughts or wishes) } \\
\hline $0=\mathrm{I}$ don't have any thoughts to kill myself & $38(95)$ & $38(95)$ & $1.000 *$ \\
\hline $1=$ I've thought to kill myself, but I was afraid to do so & $2(5)$ & $2(5)$ & \\
\hline \multicolumn{4}{|l|}{ BDI-10 (crying) } \\
\hline $0=I$ don't cry anymore like I used to & $35(87.5)$ & $27(67.5)$ & \\
\hline $1=I ' m$ crying more than usual & $1(2.5)$ & $5(12.5)$ & $0.615^{*}$ \\
\hline $2=$ I'm crying over a little problems & $2(5)$ & $8(20)$ & \\
\hline $3=I$ can't cry anymore & $2(5)$ & $0(0)$ & \\
\hline BDI-11 (agitation) & & & \\
\hline $0=\mathrm{I}$ can rest like usual & $15(37.5)$ & $19(47.5)$ & \\
\hline $1=\mathrm{I}$ feel I can't resting like usual & $22(55)$ & $16(40)$ & $0.439 *$ \\
\hline $2=$ I feel so restless, so it's hard to stay still & $3(7.5)$ & $4(10)$ & \\
\hline $3=$ I feel so restless, so I have to keep moving or doing something & $0(0)$ & $1(2.5)$ & \\
\hline BDI-12 (loss of interest) & & & \\
\hline $0=I$ have not loss interest in other people or an activities & $25(62.5)$ & $26(65)$ & \\
\hline $1=$ I have a little interest in other people or something than before & $12(30)$ & $12(30)$ & $1.000^{*}$ \\
\hline $2=I$ lost almost any interest in anyone or anything & $1(2.5)$ & $0(0)$ & \\
\hline $3=$ It's really hard to get any interest of everything & $2(5)$ & $2(5)$ & \\
\hline BDI-13 (indecisiveness) & & & \\
\hline $0=\mathrm{I}$ made decisions as well as ever & $28(70)$ & $20(50)$ & \\
\hline $1=$ I got a little hard to made a decision than I used to & $10(25)$ & $14(35)$ & \\
\hline $2=I$ got it harder to made a decision than I used to & $1(2.5)$ & $2(5)$ & $0.576^{*}$ \\
\hline $3=$ It's really hard to make any decisions & $1(2.5)$ & $4(10)$ & \\
\hline BDI-14 (worthlessness) & & & \\
\hline $0=\mathrm{I}$ do not feel that I am worthless & $33(82.5)$ & $38(95)$ & \\
\hline $1=I$ don't consider myself as worthwhile and useful as I used to & $6(15)$ & $2(5)$ & $1.000^{*}$ \\
\hline $2=$ I feel utterly worthless & $1(2.5)$ & $(0)$ & \\
\hline BDI-15 (loss of energy) & & & \\
\hline $0=\mathrm{I}$ have energy as much as ever & $24(60)$ & $20(50)$ & \\
\hline $1=I$ have less energy than I used to have & $15(37.5)$ & $19(47.5)$ & $1.000^{*}$ \\
\hline $2=I$ don't have enough energy to do many things & $1(2.5)$ & $1(2.5)$ & \\
\hline BDI-16 (changes of sleep pattern) & & & \\
\hline
\end{tabular}


Table 2: (Continued)

\begin{tabular}{|c|c|c|c|}
\hline \multirow[t]{2}{*}{ Characteristics } & \multicolumn{2}{|l|}{ Gender } & \multirow[t]{2}{*}{$\mathbf{p}$} \\
\hline & Men $n=40(\%)$ & Women $n=40(\%)$ & \\
\hline $1=$ I sleep sometimes more than usual or less than usual. & $18(45)$ & $24(60)$ & $0.141^{*}$ \\
\hline $2=I$ sleep more often than usual or I sleep much less than usual & $1(2.5)$ & $5(12.5)$ & \\
\hline \multicolumn{4}{|l|}{ BDI-17 (irritability) } \\
\hline $0=$ I'm not easily offended & $34(42.5)$ & $27(67.5)$ & \\
\hline $1=$ I'm more easily offended than ever & $5(12.5)$ & $12(30)$ & $1.000^{*}$ \\
\hline $2=I$ 'm more often offended than ever & $1(2.5)$ & $1(2.5)$ & \\
\hline \multicolumn{4}{|l|}{ BDI-18 (changes of appetite) } \\
\hline $0=I$ didn't get any changes in my appetite & $25(62.5)$ & $17(42.5)$ & \\
\hline 1=My appetite sometimes more than usual or less than usual & $14(35)$ & $20(50)$ & $1.000^{*}$ \\
\hline $2=$ My appetite is more than usual or less than usual & $1(2.5)$ & $3(7.5)$ & \\
\hline \multicolumn{4}{|l|}{ BDI-19 (concentration difficulty) } \\
\hline $0=\mathrm{I}$ can concentrated as well as usual & $27(67.5)$ & $33(82.5)$ & \\
\hline $1=I$ can't concentrated as well as usual & $12(30)$ & $5(12.5)$ & $0.270^{*}$ \\
\hline $2=$ I find it's hard to concentrated on anything for a long time period & $1(2.5)$ & $2(5)$ & \\
\hline $1=$ I feel easily tired or fatigue than usual & $17(42.5)$ & $16(40)$ & $1.000^{*}$ \\
\hline \multicolumn{4}{|l|}{ BDI-21 (loss of sexual interest) } \\
\hline $0=$ I didn't have any changes in sexual interests & $34(85)$ & $29(72.5)$ & \\
\hline $1=I ' m$ less interested in sex than before & $5(12.5)$ & $10(25)$ & $1.000^{*}$ \\
\hline $2=I ' m$ not interested in sex now & $1(2.5)$ & $1(2.5)$ & \\
\hline
\end{tabular}

*Exact fisher test. BDI: Beck Depression Inventory

mild depressive severity, the women group was larger than the men as many as 8 subjects (20\%) compared with men as many as 5 subjects $(12.5 \%)$ and in moderate severity of depression in women of 2 subjects (5\%) and men as many as 1 subject $(2.5 \%)$

\section{CONFLICTS OF INTEREST}

To determine the difference of depressive symptoms by gender in people with psoriasis. To determine the proportion of depressive symptoms by gender in people with psoriasis. To determine the severity of depressive symptoms by gender in people with psoriasis.

\section{REFERENCES}

1. Kurd SK, Troxel AB, Christoph P, Gelfand JM. The risk of depression, anxiety and suicidality in patient with psoriasis a population-based cohort study. Arch Dermatol 2010;146:891-5.

2. Independent News and Community. Indonesian Psoriasis Care Community. Available from: http://www.independentnews\&comunity. com. [Last accessed on 2014 Jan21].

3. Gupta N, Mehta K. Prevalence of depression and anxiety in patient with psoriasis. Int J Sci Res 2013;2:336-8.

4. Golpour M, Hosseini SH, Khademloo M, Ghasemi M, Ebadi A, Koohkan F, et al. Depression and anxiety disorders among patients with psoriasis: A Hospital-based case-control study. Dermatol Res Pract 2012;2012:381905.

5. Nasreen S, Ahmed I, Effendi S. Frequency and magnitude of anxiety and depression in patients with psoriasis vulgaris. J Coll Physicians Surg Pak 2008;18:397-400.

6. Sadock BJ, Sadock VA. Kaplan and Sadock Synopsis of Psychiatry Behavioral Sciences/Clinical Psychiatry. $10^{\text {th }}$ ed. Philadelphia, PA: Lippincott Williams \& Wilkins; 2007.

7. Schmitt JM, Ford DE. Role of depression in quality of life for patients with psoriasis. Dermatology 2007;215:17-27.

8. Gupta AK. Psychocutaneous disorders. In: Sadock BJ, Sadock VA, editors. Kaplan and Sadock's Comprehensive Textbook of Psychiatry. $9^{\text {th }}$ ed., Vol. II. Philadelphia, PA: Lippincott Williams \& Wilkins; 2009. p. 2423-41.

9. Tan ST. Streptococcus infection and psoriasis. Indones J Med Sci 2010;1:415-26.

10. Griffiths CE, Barker JN. Psoriasis. In: Burns T, Breathnach S, Cox N, Griffiths C, editors. Rook's Textbook of Dermatology. $8^{\text {th }}$ ed., Vol. II. Chichester: John Wiley \& Sons; 2010. p. 201-45.

11. Wardhana M. Stres psychological in psoriasis patients: A study of psychoneuroimmunology. MDVI 2012;39 Suppl 1:10-4.

12. Djuanda A. Dermatosis eritoskuamosa. In: Djuanda A, Hamzah M, Aisah S, editors. The Science of Skin and Genital Diseases $4^{\text {th }}$ ed. Jakarta: Faculty of Medical Universitas Indonesia; 2005. p. 189-203.

13. WHO. Psoriasis. WHO 2013. p. 1-4. Available from: http://www.apps. who.int/gb/ebwha/pdf files/EB133/B133 5-en.pdf. [Last accessed on 2014 Jan 21]

14. Sadock BJ. Signs and symptoms in psychiatry. In: Sadock BJ, Sadock VA, editors. Kaplan and Sadock's Comprehensive Textbook of Psychiatry. $9^{\text {th }}$ ed., Vol. I. Philadelphia, PA: Lippincott Williams \& Wilkins; 2009. p. 923-9.

15. Akiskal HS. Mood disorders: Clinical features. In: Sadock BJ, Sadock VA, editors. Kaplan and Sadock's Comprehensive Textbook of Psychiatry. $9^{\text {th }}$ ed., Vol. I. Philadelphia, PA: Lippincott Williams \& Wilkins; 2009. p. 1694-732.

16. Esposito M, Saraceno R, Giunta A, Maccarone M, Chimenti S. An Italian study on psoriasis and depression. Dermatology 2006;212:123-7.

17. National Psoriasis Foundation. Psoriasis and Mental Health Issue Brief. USA: National Psoriasis Foundation; 2012. p. 1-7.

18. Beck AT, Steer RA, Brown G. Beck Depression Inventory. $2^{\text {nd }}$ ed. Available from: http://www.harcourtassessment.com. [Last accessed on 2014 Jan6]

19. Blacker D. psychiatric rating scales. In: Sadock BJ, Sadock VA, editors. Kaplan and Sadock's Comprehensive Textbook of Psychiatry. $9^{\text {th }}$ ed., Vol. I. Philadelphia, PA: Lippincott Williams \& Wilkins; 2009. p. 1033-50.

20. Smith C, Efort BT. Test Review: Beck Depression Inventory-II. Association for Assessment in Counsuling. Available from: http://www. aac.ncat.edu/newsnotes/y98fall.html. [Last accessed on 2014 Jan6]. 